\title{
In Hospital Outcomes of Patients with ST Segment Elevation Myocardial Infarction, Late for Thrombolysis
}

\author{
Najeeb Ullah', Mehroze Sajjad², Azmat Ehsan Qureshi', Ali Ammar²
}

\begin{abstract}
Background: Myocardial infarction (MI) especially with ST segment elevation MI (STEMI) is a highly morbid and fatal entity and can result in various electrophysiological and mechanical complications during in hospital stay.

Objective: To determine the in hospital outcomes of patients with ST segment elevation myocardial infarction, late for thrombolysis.

Material and methods: This descriptive cases series was conducted at Rehmatul Lil Alameen Institute of Cardiology, PESSI, Lahore during 01-06-2018 to 31-12-2018. The cases of both genders with age 30 years or more, having ST elevation MI who were late for thrombolysis were included. The patients were looked for various outcomes like cardiogenic shock, left ventricular thrombus, heart block, death or discharge from the hospital.

Results: In this study out of 105 cases, $74(70.5 \%)$ males and $31(29.5 \%)$ females. The mean age was $58.40 \pm 11.19$ years and mean duration of hospital stay was $6.77 \pm 3.34$ days. LV clot was seen in $7(6.67 \%)$ of the cases, cardiogenic shock in $23(21.9 \%)$ and complete heart block in $4(3.81 \%)$ of the cases. Out of 105 cases, $9(8.57 \%)$ died while rest were discharged. Regarding different types of $\mathrm{MI}$, death was seen in $5(8.1 \%)$ cases in AWMI, $4(10 \%)$ in IWMI and none in LWMI out of their respective groups with $\mathrm{p}=0.81$.
\end{abstract}

Conclusion: STEMI is a highly morbid entity in cases those are late from thrombolytic and cardiogenic shock is the most common complication observed.

Key words: ST segment elevation, Myocardial infarction, Left ventricular thrombus, Cardiogenic shock.

This article may be cited as: Ullah N, Sajjad M, Qureshi AE, AmmarA. In Hospital Outcomes of Patients

with ST Segment Elevation Myocardial Infarction, Late for Thromoblysis. J Saidu Med Coll Swat 2020;10(2):111-114

\section{INTRODUCTION}

Acute coronary syndrome is one of the leading causes of cardiovascular associated death and disability. It can be divided broadly into myocardial infarction (MI) and angina pectoris depending upon the duration of chest pain and Electrocardiogram (ECG) changes. It can further be sub-classified into ST segment elevation MI (STEMI) and NSTEMI. ${ }^{1,2}$

There are multiple predisposing risk factors that can lead to a higher incidence of ischemic heart disease and include diabetes mellitus, hypertension, family history of IHD, smoking, dyslipidaemia, hyperuricemia and have a varying degree of association with disease entity and ultimately to the outcome. Early intervention in the form of pain relief, oxygenation and revascularization is the key to success. ${ }^{3,4}$

In the developed countries early percutaneous coronary intervention $(\mathrm{PCl})$ or primary $\mathrm{PCl}$ is being practiced in contrast to thrombolytic therapies which are still being practiced in the developing countries like Pakistan. Yet there are

1.University College of Medicine, The University of Lahore

2.Rehmat ul Alameen Institute of cardiology, PESSI, Lahore

Correspondence: Dr. Najeeb Ullah,

Assistant Professor of Cardiology.

University College of Medicine, The University of Lahore number of cases that report late to the window period which has shown to reveal good efficacy in cases of acute Ml. The late presentation is multi factorial i.e. lack of development of proper referral system, lack of facilities at various centres, lack of knowledge about disease, late detection of the disease, poor educational and socioeconomic factors and also the slow transportation systems are the major contributing factors for late presentation and hence late for thrombolysis.,

Early perfusion can avoid various dreadful complications as infarction and fibrosis are irreversible processes if left untreated and sequels can be devastating. There are multiple complications that can arise from acute MI with or without thrombolysis; though the number is higher in cases that lack reperfusion therapy in the form of $\mathrm{PCl}$ or thrombolysis. The major complications include heart failure, cardiogenic shock, heart blocks, arrhythmias, ventricular rupture, left ventricular thrombus (LVT) and even death in cases who do not receive the early recanalization therapy. ${ }^{5-8}$ That is why this study was planned as sensitizing concern to see the complications in cases who were late to thrombolytic therapies, so that it can raise the awareness with provided data to report early and undergo required management. 


\section{MATERIALSAND METHODS}

This was a descriptive cases series, which was conducted at Rehmatul Lil Alameen Institute of Cardiology, PESSI, Lahore during 01-06-2018 to 31-12-2018. The cases of both genders with age 30 years or more were having ST elevation MI who were late for thrombolysis (more than 12 hours of onset of symptoms) were included. The diagnosis of STEMI was made on the basis of chest pain lasting for more than 30 minutes, with new ST elevation at the $\mathrm{J}$ point in at least two contiguous leads of $=2 \mathrm{~mm}$ in men or $=1.5 \mathrm{~mm}$ in women in leads V2-V3 and/or $=1 \mathrm{~mm}$ in other contiguous chest leads or limb leads according to the American Heart Association guidelines ${ }^{2}$. The history of co morbid conditions like diabetes mellitus (DM), Hypertension (HTN), smoking and family history of premature coronary artery disease (CAD) was also taken. All the patients underwent echocardiography to look for hypoechoic area to label left ventricular thrombus (LVT), ejection fraction (EF) and cardiogenic shock was labelled on the basis of persistent hypotension and need of ionotropic support and ECG was done daily to look for any arrhythmia or heart block where the latter was labelled when there was complete asynchrony between atrial and ventricular rhythm. ${ }^{9}$ At the end the patients were looked for death or discharge from the hospital.

\section{Sample size}

Sample size was calculated as 105 by keeping the confidence level equal to $95 \%$ and the margin of error equal to $9.3 \%$ and the anticipated prevalence of left ventricular thrombosis in cases not receiving thrombolysis as $62.06 \%{ }^{8}$

\section{Statistical Analysis}

SPSS version 23.0 was used for data analysis and interpretation. Mean and SD were used for quantitative variables and frequency and percentage for qualitative variables. Post stratification chi square test was applied and $p$ value $=0.05$ was considered as significant.

\section{RESULTS}

In this study there were total 105 cases admitted. There were $74(70.5 \%)$ males and $31(29.5 \%)$ females (Table 1). The mean age of the subjects was $58.40 \pm 11.19$ years and mean duration of hospital stay was $6.77 \pm 3.34$ days as in table 1 .. There were $34.3 \%$ cases with DM, $45.7 \%$ had HTN, $47.6 \%$ were smokers and $18.1 \%$ had family history of premature (CAD). Left ventricular thrombus was seen in $7(6.67 \%)$ of the cases, cardiogenic shock in $23(21.9 \%)$ and complete heart block in $4(3.81 \%)$ of the cases. Out of 105 cases, $9(8.57 \%)$ died while rest were discharged as in figure 1. Regarding different types of $\mathrm{MI}$, death was seen in $5(8.1 \%)$ cases in Anterior wall MI (AWMI), 4 (10\%) in Inferior wall MI (IWMI) and none in Lateral wall MI (LWMI) out of their respective groups with $p=0.81$ as shown in table 2.

Table 1. Study variables $(n=105)$

\begin{tabular}{|c|c|c|}
\hline Study variables & Number & Percentage \\
\hline Male & 74 & $70.5 \%$ \\
\hline Female & 31 & $29.5 \%$ \\
\hline DM & 36 & $34.3 \%$ \\
\hline HTN & 48 & $45.7 \%$ \\
\hline Smoker & 50 & $47.6 \%$ \\
\hline Family h/o CAD & 19 & $18.1 \%$ \\
\hline Study variables & Mean \pm SD & Range \\
\hline Age & $58.40 \pm 11.19$ & $34-90$ \\
\hline Duration of hospital stay & $6.77 \pm 3.34$ & $3-16$ \\
\hline Mean Ejection fraction & $38.72 \pm 8.66$ & $20-60$ \\
\hline
\end{tabular}


Figure 1. Final outcomes $(n=105)$

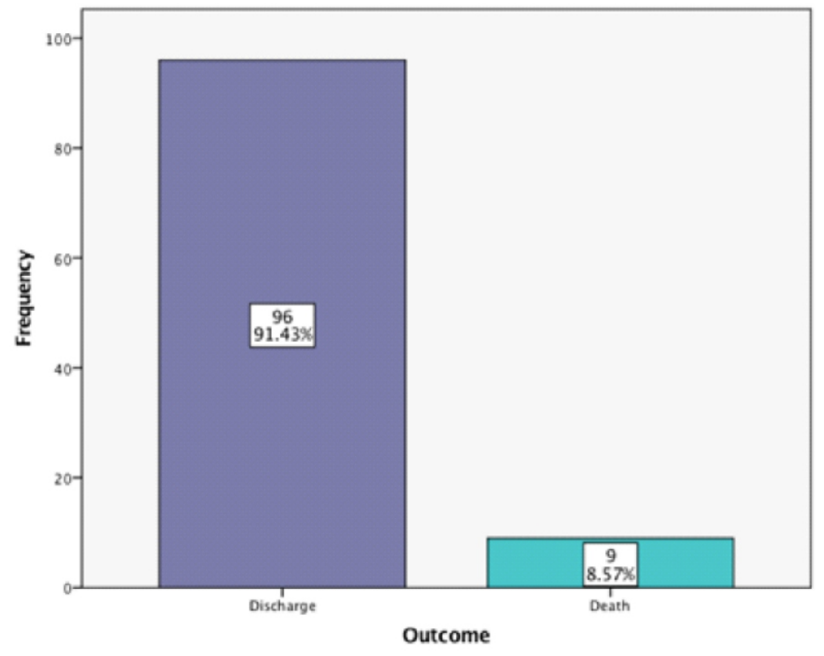

\section{DISCUSSION}

Myocardial infarction is a highly morbid and fatal condition that can result in wide degree of morbidity and mortality. Early intervention in the form of cardiac catheterization and thrombolysis both have shown an immense degree of improvement in the survival rate as well as reduction in the morbidity in such cases. ${ }^{10}$

In the present study regarding the various complications observed, left ventricular thrombus was seen in $7(6.67 \%)$ of the cases, cardiogenic shock in $23(21.9 \%)$ and complete heart block in 4 $(3.81 \%)$ of the cases. Out of 105 cases, $9(8.57 \%)$ died while rest were discharged. Regarding different types of Myocardial infarction (MI), death was seen in $5(8.1 \%)$ cases in AWMI, $4(10 \%)$ in IWMI and none in LWMI out of their respective groups with $p=0.81$.

There was limited data regarding particular variables and so was seen with the outcome in various set up in terms of mortality and morbidity.
Heart failure or cardiogenic shock was one of the most common complication seen along with arrhythmias in cases after acute myocardial infarction and even in cases that had undergone thrombolysis therapy. The overall incidence of cardiogenic shock after acute $\mathrm{Ml}$ is seen in around $25-30 \%$ and the mortality ranges from 1 to $5 \%$ of the cases which is similar to the present study. The overall mortality was seen in $8.1 \%$ of the cases in the present study, which was higher than the other studies as this study included the cases that were late for thrombolysis and their outcome was worse than the others. ${ }^{11-13}$

In this study all cases of $L V$ thrombus were seen in sub group of anterior wall MI. This was also seen by the study done by Jiang $\mathrm{Y}$ et al, where they found that out of the total cases suffering from acute MI, LVT was seen in all the cases of AWMI and furthermore they described that this event was noted in cases that had extensive AWMI with p value of $0.001 .^{14}$

According to a study done by Hashmi KA et al there were total 281 cases of acute anterior wall $\mathrm{Ml}$ and out of these thrombolysis was done in 194 cases and late for thrombolysis were 87 cases. Out of these 87 cases, LVT was seen in 54 $(62.06 \%)$ of the cases. ${ }^{8}$

In another study done by Sinha SK et al, in terms of outcome in late presenters, death was seen in 7 $(2.2 \%)$ of the cases. cardiogenic shock was observed in $59(4.9 \%)$ of the cases and AV block was observed in $4.5 \%$ of the cases overall. ${ }^{15}$

In the present study complete heart block was observed in overall $4(3.81 \%)$ of the cases and all of these cases suffered from inferior wall MI. These findings were again in line with the results

Table 2. Outcome vs type of MI $(n=105)$

\begin{tabular}{|c|c|c|c|}
\hline \multirow{2}{*}{ Type of MI } & \multicolumn{2}{|c|}{ Outcome } & \multirow{2}{*}{ p Value } \\
\cline { 2 - 3 } & Discharge & Death & \\
\hline AWMI & $57(91.9 \%)$ & $5(8.1 \%)$ & \multirow{2}{*}{0.81} \\
\hline IWMI & $36(90 \%)$ & $4(10 \%)$ & \\
\hline LWMI & $3(100 \%)$ & $0(0 \%)$ & \\
\hline Total & 96 & 9 & \\
\hline
\end{tabular}


of the previous studies. According to a study done by Hashmi KA et al it was seen that complete heart block was seen in $13(7.3 \%)$ of the cases which was slightly higher in their study. ${ }^{13}$ The reason was found that they had more cases suffering from IWMI, which was found to be a significant predictor to lead to complete heart block in previous studies. ${ }^{16,17}$

\section{CONCLUSION}

STEMI can be a highly morbid entity in cases those are late for thrombolytic and cardiogenic shock is the most common complication observed. Efforts are needed in all aspects to reduce pre and in-hospital delays in management of STEMI with reperfusion therapy.

\section{REFERNCES}

1. Dai X, Bumgarner J, Spangler A. Acute ST-elevation myocardial infarction in patients hospitalized for noncardiac conditions. J Am Heart Assoc 2013; 2:e000004.

2. Investigators A: Management of acute coronary syndromes in developing countries: acute coronary events-a multinational survey of current management strategies. Am Heart J 2011;162(5):8529. e22.

3. Rapsomaniki E, Timmis A, George J. Blood pressure and incidence of twelve cardiovascular diseases: lifetime risks, healthy life-years lost, and age-specific associations in 1.25 million people. Lancet 2014; 383:18991-1923.

4. Kaul P, Federspiel JJ, Dai X. Association of inpatient vs outpatient onset of ST-elevation myocardial infarction with treatment and clinical outcomes. JAMA 2014; 312:1999-2012.

5. Benjamin EJ, Virani SS, Callaway CW. Heart Disease and Stroke Statistics-2018 Update: A Report From the American Heart Association. Circulation 2018-137:e67.

6. Lemkes JS, Janssens GN, van der Hoeven NW. Timing of revascularization in patients with transient STsegment elevation myocardial infarction: a randomized clinical trial. Eur Heart J 2019; 40:283-298.

7. Siemieniuk RAC, Chu DK, Kim LH. Oxygen therapy for acutely ill medical patients: a clinical practice guideline. BMJ 2018; 363:k4169

8. Hashmi K A, Saeed H Y, Ahmed J. Left Ventricular Thrombus Formation in Acute Anterior Wall Myocardial Infarction: A Comparison Between Thrombolyzed and Non-Thrombolyzed Patients. Cureus. 2020;12(7):e9090.

9. Rihal CS, Naidu SS, Givertz MM, Szeto WY, Burke JA, Kapur NK. Society for Cardiovascular Angiography and Interventions (SCAI), Heart Failure Society of America (HFSA), Society of Thoracic Surgeons (STS), American Heart Association (AHA), and American College of Cardiology (ACC) . 2015 SCAI/ACC/HFSA/STS clinical expert consensus statement on the use of percutaneous mechanical circulatory support devices in cardiovascular care: endorsed by the American Heart Assocation, the Cardiological Society of India, and Sociedad Latino Americana de Cardiologia Intervencion; Affirmation of
Interventional Cardiology-Association Value by the Canadian Association of Canadienne de Cardiologie d'intervention. J Am Coll Cardiol. 2015; 65:7-26.

10. O'Gara PT, Kushner FG Ascheim DD, Casey DE, Chung MK, de Lemos JA, et al. 2013 ACCF/AHA guideline for the management of ST-elevation myocardial infarction: a report of the American College of Cardiology Foundation/American Heart Association Task Force on Practice Guidelines. Circulation. 2013;127(4):362-425.

11. Schröder K, Zeymer U, Wegschneider K, Schroder R. Prediction of outcome in ST elevation myocardial infarction by the extent of ST segment deviation recovery. Which method is best?[in German] Z Kardiol. 2004;93:595-604.

12. $\mathrm{Li} \mathrm{Q}, \mathrm{Yu} \mathrm{X}, \mathrm{He} \mathrm{J}$. The relationship between revascularization extent and the long-term prognosis of patients with stable angina pectoris and three-vessel disease treated by percutaneous coronary intervention in the era of drug-eluting stents. Clin Cardiol. 2014;37:566-575.

13. Codner P, Bental T, Assali A. Long-term comparative analysis from an all-comer cohort of coronary patients treated using first- and second-generation drug-eluting stents. J Invasive Cardiol. 2014;26:378-384.

14. Fan $Y$, Bai X, Chen $Y$, Shen $G$, Lu Q, Wan Z. late percutaneous coronary intervention prevent left ventricular remodelling and improved clinical outcomes in patients with ST elevation myocardial infarction. Clin Cardiol. 2015;38:82-91.

15. Sinha SK, Krishna V, Thakur R, Kumar A, Mishra V, Jha $M J$, et al. Acute myocardial infarction in very young adults: A clinical presentation, risk factors, hospital outcome index, and their angiographic characteristics in North India-AMIYA Study. ARYA Atherscler. 2017;13(2):79-87.

16. Hashmi KA, Shehzad A, Hashmi AA, Khan A. Atrioventricular block after acute myocardial infarction and its association with other clinical parameters in Pakistani patients: an institutional perspective. BMC Res Notes. 2018;11:329.

17. Iqbal MA, Hadi A, Ahmad F, Shah ST, Haq MR, IqbalA, et al. Conduction disturbances in patients with acute anterior wall myocardial infarction and in-hospital outcomes. Pak Heart J. 2014;47(3):156-161. 